\title{
Association between Inactive-Gymnastics and Active- Gymnastics Elderly towards Cognitive Functions Measured by The Mini-Mental State Examination (MMSE)
}

\author{
Muhammad Hamdan ${ }^{1}$, Raini Wisnujono ${ }^{1}$, Yudha Haryono ${ }^{1}$, Abdulloh Machin ${ }^{1}$, Ichwanuddin ${ }^{1}$ \\ ${ }^{I}$ Department of Neurology, Faculty of Medicine, Universitas Airlangga, Dr. Soetomo General Hospital, \\ Surabaya, 60285 Indonesia
}

\begin{abstract}
Background : The decline of cognitive function is a problem that often experienced by the elderly. Objectives : to determine the role of elderly gymnastics towards cognitive function.

Methods : A total of 50 elderly patients that fulfilled the inclusion and exclusion criteria in Kedurus village, Surabaya, from September to October 2013 were conducted. The cognitive function was examined using The Mini-Mental State Examination (MMSE) and the results were allocated to two groups: the case group with the MMSE score less than 26/30 while MMSE control group from 27/30.

Results : During the study, 50 subjects were enrolled ( 25 case groups and 25 control groups). It was obtained in case group that did inactive-gymnastics was $15(60 \%)$ and active-gymnastics was $10(40 \%)$, with $\mathrm{P}=$ 0.047 and OR 3.188 (CI 0.99-10.17)
\end{abstract}

Conclusion : There was no significant correlation between inactive-gymnastics elderly and activegymnastics towards cognitive function.

Keywords: Cognitive Function, Elderly, Gymnastics Elderly

\section{Introduction}

The structure of the world's population including Indonesia is currently towards the aging process that characterized by the increasing number and proportion of the elderly population. The proportion of elderly people in Indonesia has increased significantly over the last 30 years with a population of 5.3 million people (4.48 percent of the total Indonesian population) in 1971 to 19.3 million ( 8.37 percent of the total Indonesian population) in $2009^{1}$.

\section{Corresponding Author: \\ Muhammad Hamdan}

Corresponding author's address : Department of Neurology, Faculty of Medicine, Universitas Airlangga, Dr. Soetomo General Hospital, Mayjen Prof. Dr.Moestopo Street 47, Surabaya City, 60131, Indonesia e-mail : muhammadhamdan.md@gmail.com
The aging process is a natural process that characterized by a decrease or changes in physical, psychological and social conditions in interacting with others. The aging process will occur continuously naturally from birth to aging. The aging process is not a disease but is a process of decreasing the body's resistance in the face of internal and external stimuli of the body ${ }^{2}$.

However, most of the elderly process is still within normal limits due to the plasticity process. This process is the ability of a related brain structure and function to keep developing because of stimulation. Therefore, in order not to quickly back off this plasticity process, it must be maintained ${ }^{3}$.

One attempt to inhibit cognitive deterioration due to aging is by doing sports movement or physical exercise. Truthfully, someone grows old because they do not want to move. Exercise could increase the potential work of 
the brain is improving general physical fitness in the form of brain exercise that intellectually stimulating activity who aims to maintain brain health by doing bodybuilding ${ }^{4}$.

Structured and programmed movement learning is used to stimulate different learning centers in the brain. Movements that cause left and right hemisphere functions work together is to strengthen the correlation between the two hemispheres. Movements across the midline of the body could integrate the two hemispheres of the brain so that the brain is able to organize itself ${ }^{5}$

There are many factors that affect cognitive abilities in elderly. It is stated that by living a healthy lifestyle and exercising the body and mind of the elderly could slow down the process of mental decline. In general, we could argue that activity is a key factor in maintaining a quality of life in elderly. Maintaining mental fitness is considered to be important in the continuous quality of life of the elderly ${ }^{6}$.

Other studies have reported that some physical activity might cause the changes in the brain structure (increasing the number of neurons and branched dendrites). It also reported that in the elderly through aerobic exercise (brisk walking of an hour walking) or yoga-type stretching could improve their cognitive function on cognitive tests ${ }^{7}$,

Provision of exercise in the elderly began with the light intensity and time then increased slowly and ut tend to uncompetitive/compete. Sports exercise for the elderly has great benefits because it could increase aerobic ability that will increase the flow and volume of blood supply that carries oxygen to the organs of the body especially to the brain organ ${ }^{8}$.

This study aims to determine the correlation between inactive-gymnastics elderly and active-gymnastics elderly toward cognitive function as measured by The Mini-Mental State Examination(MMSE).

\section{Methods}

This research was an observational analytic research using case-control design which implemented in September 2013 to October 2013 in Kedurus District of Surabaya. All elderly people who follow both inactive and active-gymnastics that meet the criteria for inclusion and exclusion were used as the samples.

The control inclusion criteria were; Aged 6070 years, Men and Women, more than 27 for MMSE scores. The exclusion criteria for the control of this study were among others were; Brain tumor, moderate to severe brain injury, stroke, Not willing to participate in the research. Exclusion criteria of case research were; Experiencing cognitive impairment with obvious causes of structural lesions (brain tumor, moderate to severe brain injury, stroke), Unwilling to take part in research.

The independent variables were inactive-gymnastics elderly and active-gymnastics elderly. The dependent variable was the cognitive function that measured by MMSE while confounding variables were diabetes mellitus, hypertension, heart disease, uncontrolled dyslipidemia, education, smokers, alcohol drinkers.

Prior to conducting this study, the researcher had a data retrieval procedure as well as a pickup flow that began by selecting the appropriate elderly in the inclusion criteria and given an explanation of the purpose and usefulness about this study research, then asked to participate without coercion. At the end of the explanation, the subject asked to read, ask about things that have not been understood yet. If they have understood and agreed, then they were required to sign an approval letter. Examination of cognitive function was performed by MMSE. If there were things that have not been understood or less clear, it could be asked back to the doctor who gives an explanation (Resident intraining I neurology by giving a phone number).

All recording results were collected for further data tabulation and statistical analysis. Collected categorical data were analyzed by using chi-square test while numerical data were analyzed by unpaired t-test. This study used SPSS 17.0 program.

\section{Results}

All study subjects performed to recording demographic data including sex, age, last education, and type of jobs. All elderly were-examined for cognitive function by using MMSE. There were 50 subjects consisting of 25 subjects with normal MMSE results that called as controls and 25 subjects with disturbed MMSE results that referred to as cases. 


\section{Demography data}

There were 50 subjects which consist of 25 subjects for case group and 25 subjects for the control group.

Characteristic of Research Subject Based on Mean Age

The mean age of case study subjects was $63.60 \pm 4.093$ years, while the control group was $63.40 \pm 3.617$ years $(\mathrm{P}=0.333)$ shown in table 1.

Table 1. Characteristics of study subjects based on mean age

\begin{tabular}{|l|l|l|l|l|}
\hline \multirow{2}{*}{} & \multicolumn{2}{l|}{ Cognitive Function } & \multicolumn{2}{l|}{ Pontrol } \\
\cline { 2 - 5 } & \multicolumn{2}{l|}{ Case } & Mean & Std.Intersection \\
\hline & Mean & Std.Intersection & 63,40 & 3,617 \\
\hline Age & 63,60 & 4,093 & 0.333 \\
\hline
\end{tabular}

Clinical data

\section{Characteristics of Research Subjects Based on Mean of Systolic Blood Pressure}

Characteristics based on blood pressure was in table 4, in the case group the mean of systolic blood pressure was $137.60 \pm 7.234$ and in the control group was $133.20 \pm 10,693$ with $\mathrm{p}=0.051$.

Table 2. Characteristics of research subjects based on mean systolic blood pressure

\begin{tabular}{|l|l|l|l|l|l|}
\hline \multirow{2}{*}{} & \multicolumn{2}{l|}{ Cognitive Function } & \multicolumn{2}{l|}{ P } \\
\cline { 2 - 5 } & \multicolumn{2}{l|}{ Case } & \multicolumn{2}{l|}{ Control } & \multicolumn{2}{l|}{} \\
\hline & Mean & Std.Intersection & Mean & Std.Intersection \\
\hline TD & 137,60 & 7,234 & 133,20 & 10,693 & 0.051 \\
\hline
\end{tabular}

Characteristics of Research Subjects Based on Mean of Systolic Blood Pressure

Characteristics based on smoking risk factors in case group was $3(12 \%)$ and control was 1 (4\%), while nonsmokers in case group was $22(88 \%)$ and control was $24(96 \%)$ with $\mathrm{P}=0.297$, in table 3 .

Table 3. Characteristics of research subjects based on smoking risk factors

\begin{tabular}{|c|c|c|c|c|}
\hline & \multicolumn{2}{|c|}{ Cognitive Function } & \multirow{2}{*}{ Total } & \multirow{2}{*}{$\mathbf{P}$} \\
\hline & Case & Control & & \\
\hline $\begin{array}{l}\text { Smoking } \\
\text { Yes } \\
\text { No }\end{array}$ & $\begin{array}{l}3(12 \%) \\
22(88 \%)\end{array}$ & $\begin{array}{l}1(4 \%) \\
24(96 \%)\end{array}$ & $\begin{array}{l}4 \\
46\end{array}$ & 0.297 \\
\hline Total & $25(100 \%)$ & $25(100 \%)$ & 50 & \\
\hline
\end{tabular}




\section{Mean of Random Blood Glucose Level (GDA) on study subjects}

Characteristics of subjects based on random blood glucose levels have obtained the mean in the case group was $115.32 \pm 55.426$ and in the control group was $101.92 \pm 45.767$, with $\mathrm{P}=0.101$.

Table 4 Mean of Blood Glucose Ratios (GDA) in the study subjects

\begin{tabular}{|l|l|l|l|l|l|}
\hline \multirow{2}{*}{} & \multicolumn{2}{l|}{ Cognitive Function } & \multicolumn{2}{l|}{ P } \\
\cline { 2 - 5 } & \multicolumn{2}{l|}{ Case } & \multicolumn{2}{l|}{ Control } & \multicolumn{2}{l|}{} \\
\hline & Mean & Std.Intersection & Mean & Std.Intersection \\
\hline GDA & 115,32 & 55,426 & 101,92 & 45,767 & 0.101 \\
\hline
\end{tabular}

Characteristics of subjects based on mean serum LDL levels

Characteristics of subjects based on serum LDL levels, in the case group, have obtained mean was $120.12 \pm$ 20.547 and in the control group was $120.60 \pm 29.364$ with $p=0.177$.

Table 5. Characteristics of subjects based on mean serum LDL levels

\begin{tabular}{|l|l|l|l|l|l|}
\hline \multirow{2}{*}{} & \multicolumn{2}{l|}{ Cognitive Function } & \multicolumn{2}{l|}{ P } \\
\cline { 2 - 5 } & \multicolumn{2}{l|}{ Case } & \multicolumn{2}{l|}{ Control } & \multicolumn{2}{l|}{} \\
\hline & Mean & Std.Intersection & Mean & Std.Intersection & 0.177 \\
\hline LDL & 120,12 & 20,547 & 120,60 & 29,364 & 0 \\
\hline
\end{tabular}

Correlation of inactive-gymnastics elderly and active-gymnastics elderly toward cognitive function

The differences in cognitive function in case group inactive-gymnastics elderly was 15 (60\%) and 10 (40\%) of active-gymnastics elderly, $(\mathrm{p}=0.047)$.

Table 6. Correlation of inactive-gymnastics elderly and active-gymnastics elderly toward cognitive function

\begin{tabular}{|c|c|c|c|c|c|c|}
\hline & \multicolumn{4}{|c|}{ Cognitive Function } & \multirow{3}{*}{$\mathbf{p}$} & \multirow{3}{*}{ RO (IK 95\%) } \\
\hline & \multicolumn{2}{|l|}{ Case } & \multicolumn{2}{|c|}{ Control } & & \\
\hline & $\mathbf{N}$ & $\%$ & $\mathbf{n}$ & $\%$ & & \\
\hline $\begin{array}{l}\text { Activ } \\
\text { Yes } \\
\text { No }\end{array}$ & $\begin{array}{l}10 \\
15\end{array}$ & $\begin{array}{l}40 \\
60\end{array}$ & $\begin{array}{l}17 \\
8\end{array}$ & $\begin{array}{l}68 \\
32\end{array}$ & 0.047 & $3,188(0.99-10.17)$ \\
\hline Total & $25 \quad 100$ & & 25 & & & \\
\hline
\end{tabular}

There was also an OR of 3,188 - (CI 95\% 0.999 - 10,171), so the subjects of inactive-gymnastics elderly had OR for cognitive impairment by 3.18 times compared to the active-gymnastics elderly, but not statistically significant 
because they contained a number 1 in the interval confidence $(95 \%$ CI 0.999 - 10,171).

\section{Discussion}

In the basic data characteristic of subjects, there was no significant difference in some basic variables, in this study was attempted to all subjects in almost equal condition, wish to minimize the influence of other factors that will affect cognitive function.

In one study linking physical activity and decreased risk of Cognitive Impairment (CI), in elderly there was a difference between women who did high physical activity to decreased risk of Cognitive Impairment (CI) (OR 0.58; 95\% CI, 0.40-0.82) and at men no significant difference, this was due to the elderly women occur menopause which very influential on lipid profiles, so that physical activity in elderly was very useful to keep the occurrence of decreased cognitive function, especially in women ${ }^{9}$.

From age characteristic in both groups, there was no difference of mean age between case group and control. According to WHO a person has been categorized as elderly at age 60 years and above. In this research was limited to the age range of 60 to 70 years, and the mean age of study subjects was almost the same $(63.60 \pm 4.093$ years) compared to the control group $(63.40 \pm 3.617$ years). There was no significant difference between case group and control group with $\mathrm{p}=0.333$.

Characteristics of education level were divided into four groups; elementary school, junior high school, senior high school, and college. The higher the level of education then the cognitive function will be better ${ }^{10}$. Characteristics of education level were divided into the level of education; elementary school, junior high school, senior high school, and college. The higher the level of education then the cognitive function will be better ${ }^{10}$. The comparison of the level of education obtained at the level of elementary education was $13(52 \%)$ people in the cases group larger than the junior high school and senior high school level but in this study, there was no significant correlation $\mathrm{P}=0.163$.

The characteristics of the type of job status were; unemployed in case group was $23(92 \%)$, in control group was $22(88.0 \%)$. In the employee was obtained in case group by $2(8,0 \%)$ and the control group by 3 ( $12 \%$ ) while in the unemployed group, the percentage of cases was greater and in the working group. This in accordance with studies that stated, still working after retirement could sustain the elderly cognitive function, unemployed elderly have poor cognitive performance, which found from $41 \%$ of 50-60 year unemployed have the ability to recall memory compared to that the employee one ${ }^{11}$.

Smoking as a confounding factor against cognitive dysfunction, in a study that conducted to search at the smoking correlation with cognitive function, was found that smoking causes a 0.13 point/year drop in MMSE values compared to non-smokers. There was no significant correlation with $\mathrm{P}=0.297$, this might be due to men smoke more and most of them inactive at gymnastics.

Mean of systolic blood pressure, in case group was $137,60 \pm 7,234$ and in control group was 133,20 $\pm 10,693$, there was no significant difference in both groups with $\mathrm{p}$ $=0,051$. In a study that looks at the correlation between hypertension and cognitive function, the mean of MMSE values was lower in the hypertension group by $25.9 \pm 3.9$ than in the normal blood pressure group. This decrease in cognitive function was correlated to vascular damage by arteriosclerosis in large vessels and stress oxidative properties in blood vessel walls ${ }^{12}$.

Mean of random blood sugar level with cognitive function has no significant difference in both groups, in case group by $115,32 \pm 55,42$ and in control group by $101,92 \pm 45,767$ with value $\mathrm{p}=0.101$. In a study that correlates blood sugar level and cognitive function has obtained the correlation between high blood sugar levels with decreased cognitive function ${ }^{13}$.

Mean of serum LDL level with cognitive function has no difference in both groups, in case group was $120,12 \pm 20,547$ and in control group was $120,60 \pm 29,36$ with $\mathrm{p}=0.177$. In a study that linking Lipid profile and cognitive function with LDL case group $130.5 \pm 29.6$ and control $112.3 \pm 35.6$ has a significant correlation to cognitive function decline with $\mathrm{p}=0.038^{14}$.

Examination of cognitive function was by using MMSE score which one of cognitive aspect examination of mental function, orientation, registration, attention, 
vigilance recall, visuospatial and language used was to assess the change of cognitive function ${ }^{13}$, ideally, a measuring instrument has sensitivity and high specificity. The MMSE values was under 27/30 considered as abnormal and indicate cognitive impairment, while the values under 24/30 were suspected of a Dementia Syndrome ${ }^{15}$.

In this study, there was no statistically significant correlation between inactive-gymnastics elderly and active-gymnastics elderly to cognitive function, with CI $95 \%$ (0.999 - 10.171). According to WHO (2010), there were various activities that could perform by elderly to maintain cognitive function such as walking activity, cycling, doing daily tasks at home and play activities, so gymnastics was not the only physical activity that required by elderly to maintain cognitive function and fitness, activity is a key factor in maintaining quality of life in old age ${ }^{6}$

\section{Conclusion}

There was no correlation between inactivegymnastics elderly and active-gymnastics elderly with cognitive function.

Ethical Clearance: The present study was carried out in accordance with the research principles. This study implemented the basic principle ethics of respect, beneficence, nonmaleficence, and justice.

Conflict of Interest: None declared

Source of Funding: This study is done with individual funding.

\section{Reference}

1. Usia KNL. Profil penduduk lanjut usia 2009. Jakarta: Komnas Lansia. 2010;

2. Miller CA. Nursing for wellness in older adults. Lippincott Williams \& Wilkins; 2009.

3. Kusumoputro S, Sidiarto LD, Samino H, Munir R, Nugroho W. Kiat panjang umur dengan gerak dan latih otak. Jakarta: UI-Press; 2003.

4. Markam S. Latihan vitalisasi otak. Grasindo; 2005.

5. Madigan JB. Action based learning: Building better brains through movement. Retrieved from abllab. com/wp-content/themes/abl/doc/abl-handout. pdf; 2009.

6. Cusack SA, Thompson WJA, Rogers ME. Mental fitness for life: Assessing the impact of an 8-week mental fitness program on healthy aging. Educational Gerontology. 2003;29(5):393-403.

7. Karlawish JHT, Clark CM. Diagnostic evaluation of elderly patients with mild memory problems. Annals of Internal Medicine. 2003;138(5):411-9.

8. Van Gelder BM, Tijhuis MAR, KalmijnS, Giampaoli S, Nissinen A, Kromhout D. Physical activity in relation to cognitive decline in elderly men: the FINE Study. Neurology. 2004;63(12):2316-21.

9. Laurin D, Verreault R, Lindsay J, MacPherson K, Rockwood K. Physical activity and risk of cognitive impairment and dementia in elderly persons. Archives of neurology. 2001;58(3):498-504.

10. Atkinson RL, Atkinson RC, Hilgard ER. Pengantar Psikologi (terjemahan Taufiq, N dan Barhana, R). Jakarta: Penerbit Erlangga. 1991;

11. O'Sullivan V, Nolan B, Barrett A, Dooley C. Income and wealth in the Irish longitudinal study on ageing. The Economic and Social Review. 2014;45(3, Autumn):329-48.

12. Giordano N, Tikhonoff V, Palatini P, Bascelli A, Boschetti G, De Lazzari F, et al. Cognitive functions and cognitive reserve in relation to blood pressure components in a population-based cohort aged 53 to 94 years. International journal of hypertension. 2012;2012.

13. Haan MN. Therapy Insight: type 2 diabetes mellitus and the risk of late-onset Alzheimer's disease. Nature Reviews Neurology. 2006;2(3):159.

14. TEKIN O, ÖZKARA A, Yanik B, YİĞİTOĞLU MR, Ilhan A, Kibrisli E, et al. Effects of plasma lipids and smoking on cognitive function. Turkish Journal of Medical Sciences. 2011;41(2):193-204.

15. Perneczky R, Wagenpfeil S, Komossa K, Grimmer T, Diehl J, Kurz A. Mapping Scores Onto Stages: Mini-Mental State Examination and Clinical Dementia Rating. The American Journal of Geriatric Psychiatry [Internet]. 2006;14(2):139-44. Available from: http://www.sciencedirect.com/ science/article/pii/S1064748112605442 